\title{
REINFORCED CONCRETE SLAB WITH SUBSOIL: NUMERICAL MODELLING AND EXPERIMENT
}

\author{
Marcalikova Z.*, Kozielova M.**, Smirakova M.***, Cajka R. ${ }^{* * * *}$
}

\begin{abstract}
The paper is focused on the issue of modelling reinforced concrete slab in the interaction with the subsoil. It is a specific task that includes the design of concrete structure and geotechnical analysis. The aim of the paper is to analyze the effects of parameters of subsoil in nonlinear analysis. Specifically, a parametric study for different subsoil depths and subsoil modulus of elasticity is elaborated. For numerical modelling, an experiment of the reinforced concrete slab with dimensions of $2000 \times 2000 \mathrm{~mm}$ and thickness of $150 \mathrm{~mm}$ was chosen, which was tested on a specialized device at Technical University of Ostrava. The concrete slab is reinforced with steel reinforcement. Nonlinear analysis with utilization of finite element method is chosen to solve the $3 D$ numerical model, where the fracture-plastic material model is chosen for concrete.
\end{abstract}

Keywords: Numerical modelling, Slab, Subsoil, Reinforcement, Concrete.

\section{Introduction}

Soil Structure Interaction (SSI) includes research two area, i.e. design and analysis of concrete structure (Cajka et al., 2020 and Kozielova et al., 2020) and geotechnics - subsoil analysis (Hrubesova et al., 2018 and Pazdera et al., 2019). SSI is particularly important in the case of specific foundation conditions or subsoil, extreme load (Kralik, 2016) or dynamic analysis (Kotrasova et al., 2017). For this reason, knowledge of the manner of failure (Siburg et al., 2014 and Sucharda et al., 2018a) and the possibilities of using advanced computational models (Cajka, 2014 and Tomasovicova et al., 2017) are important. In the field of SSI research, attention is paid mainly to experimental research, which is focused on shear failure in concrete structures (Hegger et. al., 2007 and Buchta et al., 2015). However, the solution is only suitable for simple selected tasks. In particular, however, numerical modeling is developing (Cervenka et al., 2016). In the detailed SSI analysis, it is necessary to take into account the choice of a computational model, material model (Sucharda, 2020) subsoil stiffness, interaction modelling and interface and subsoil between these systems (Tomasovicova et al., 2017). Also important is the choice of a concrete model that takes into account cracking and shear failure or punching (Augustin et al., 2018 and Hoang et al., 2016). In summary, this to the use of nonlinear analysis and finite element method. The solution of the finite element method itself can be modified for nonlinear analysis, where the incremental solution is chosen for the calculation:

$$
\mathbf{K}(\mathbf{u}) \cdot \Delta \mathbf{u}_{\mathbf{i}}=\Delta \mathbf{F}_{\mathbf{i}}
$$

where $\mathbf{K}(\mathrm{u})$ is the stiffness matrix of the structure dependent on the displacement vector $\mathrm{u}, \Delta \mathbf{u}_{\mathrm{i}}$ is the deformation increment for the load step $\Delta \mathbf{F}_{\mathrm{i}}$. However, it is advisable to follow the recommendations (fib Model Code 2010 and Sucharda et al., 2018b) for modelling concrete structures. For the analyzed problem is important, that appropriate size of the modelled subsoil and its input parameters enter the calculation.

* Ing. Zuzana Marcalikova: VSB -Technical University of Ostrava, Faculty of Civil Engineering, Department of Structures, Ludvíka Podéště 1875/17, 70800 Ostrava-Poruba, Czech Republic, zuzana.marcalikova@vsb.cz

** Ing. Marie Kozielova, PhD.: VSB -Technical University of Ostrava, Faculty of Civil Engineering, Department of Structures, Ludvíka Podéště 1875/17, 70800 Ostrava-Poruba, Czech Republic, marie.kozielova@vsb.cz

*** Ing. Martina Smirakova, PhD.: VSB -Technical University of Ostrava, Faculty of Civil Engineering, Department of Structures, Ludvíka Podéště 1875/17, 70800 Ostrava-Poruba, Czech Republic, martina.smirakova@vsb.cz

**** Prof. Ing. Radim Cajka, CSs.: VSB -Technical University of Ostrava, Faculty of Civil Engineering, Department of Structures, Ludvíka Podéště 1875/17, 70800 Ostrava-Poruba, Czech Republic, radim.cajka@vsb.cz 

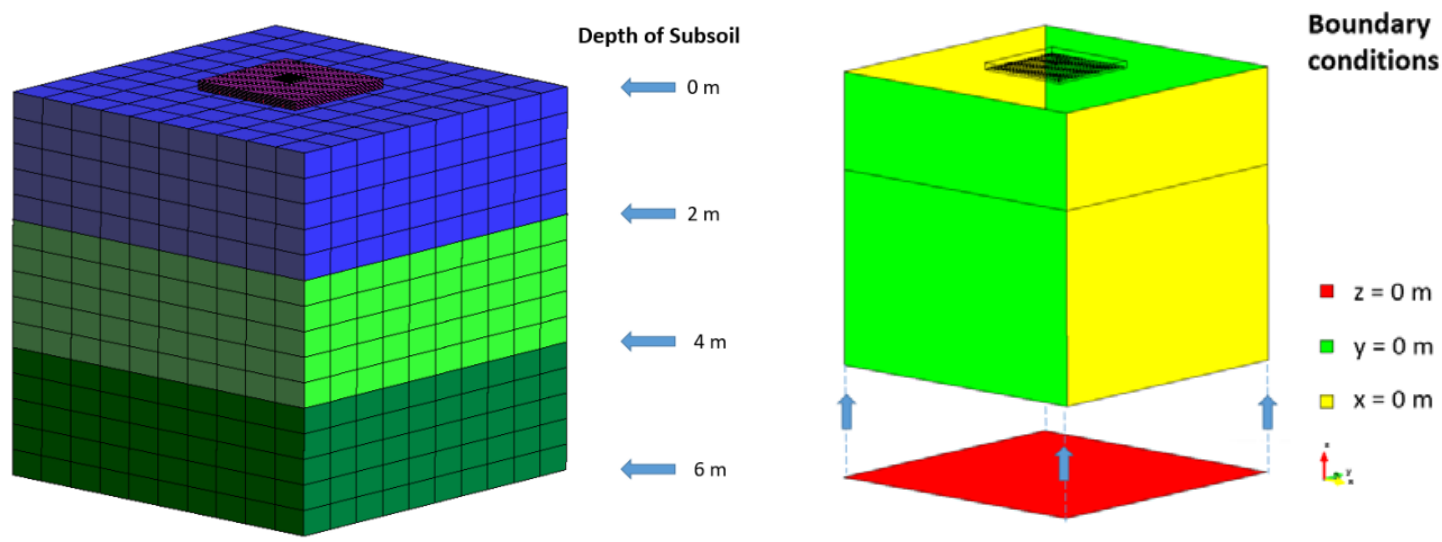

Fig. 1: Computer model and boundary conditions.

\section{Numerical modelling}

The performed study is based on a non-linear analysis involving a 3D computational model with a loading steel plate, reinforced concrete slab and subsoil. The calculations are conducted for a variable subsoil depth of 2 to $6 \mathrm{~m}$ and a modulus of subsoil elasticity of 10 to $30 \mathrm{MPa}$. The finite element mesh has a regular shape. Computer model and boundary conditions are shown in Fig. 1. The detail of the finite element mesh is shown in Fig. 2. The ground plan size of the model was $6 \times 6 \mathrm{~m}$. Concrete parameters respect to Model Code 2010 and user manual Atena (Cervenka et al., 2016). A contact interface is modeled between the concrete slab and subsoil. The load was applied by force in steps of $10 \mathrm{kN}$. There is graphic output of crack occurrence and stress on the slab in Fig. 3.

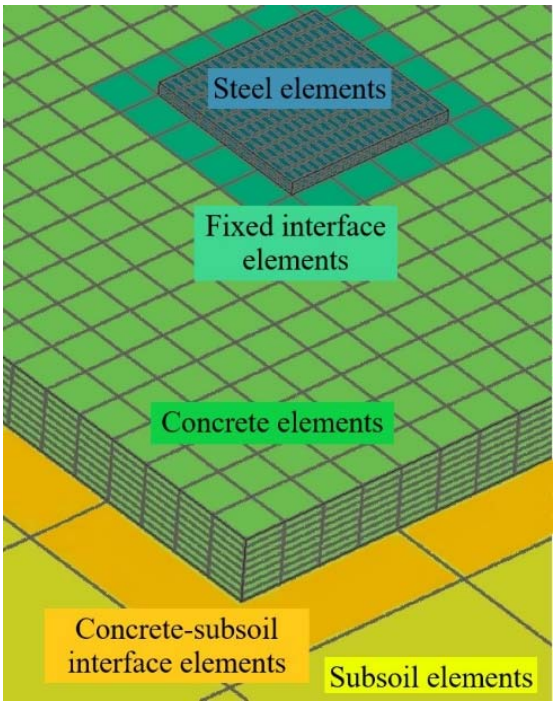

Fig. 2: Detail of computer model.
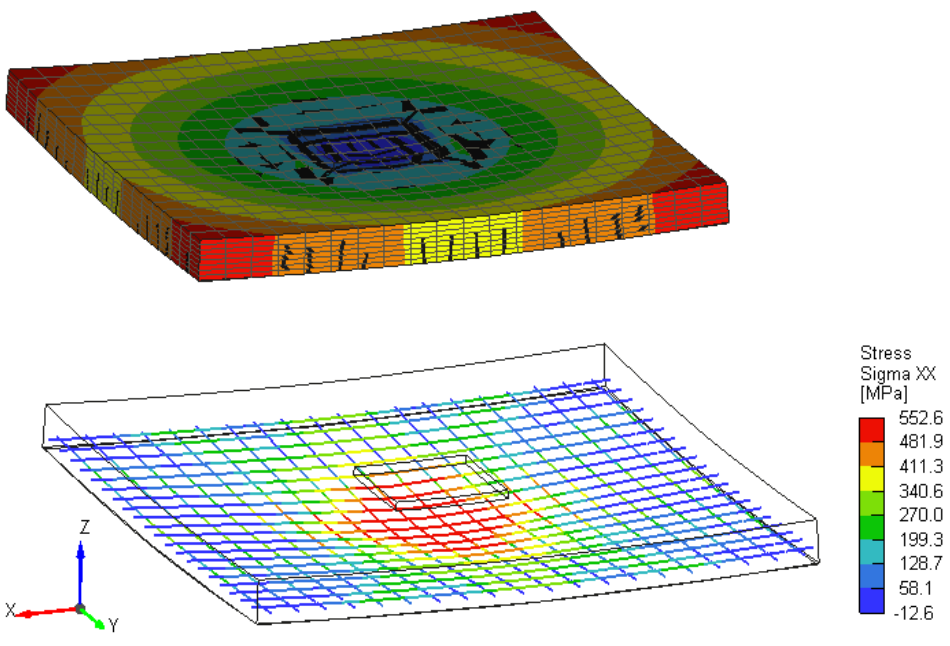

Fig. 3:RC slab with crack and reinforcement.

\section{Experiment}

For numerical modelling was chosen experiment (Buchta et al., 2015) with a reinforced concrete slab with dimensions 2000 × $2000 \mathrm{~mm}$ and thickness $150 \mathrm{~mm}$. The experiment is shown in Fig. 4. The reinforced concrete slab was loaded centrally and was made of class C35/45 concrete. The reinforcement is of a $\varnothing 8 / 100 \mathrm{~mm}$ steel mesh, see Fig. 5. The subsoil was classified as clay soil. Specialized testing equipment is located at the Faculty of Civil Engineering, VSB - Technical University of Ostrava (Czech Republic). The testing equipment is designed for loads up to $1000 \mathrm{kN}$ and also includes a measuring and control panel for hydraulic cylinder. A total of 16 sensors were used in the test. For evaluation in paper used 5 sensors in the blue line in Fig. 4 was used for the presented contribution. The $300 \mathrm{kN}$ and $750 \mathrm{kN}$ loading steps were selected for comparison of results numerical model and experiment. The value of $300 \mathrm{kN}$ was chosen with respect to the calculation of the bending moment, which was $285 \mathrm{kN}$. The $750 \mathrm{kN}$ value was the last load 
step in the experiment. At $750 \mathrm{kN}$, cracks were visible in the slab, but the slab remained compact. During the experiment, the reinforcement was not interrupted, only plastic deformations occurred. The resulting deformation, see Fig. 6, curves were evaluated for the cross-section corresponding to the sensors from 03 to 07 - corresponding to the blue line in Fig. 4.

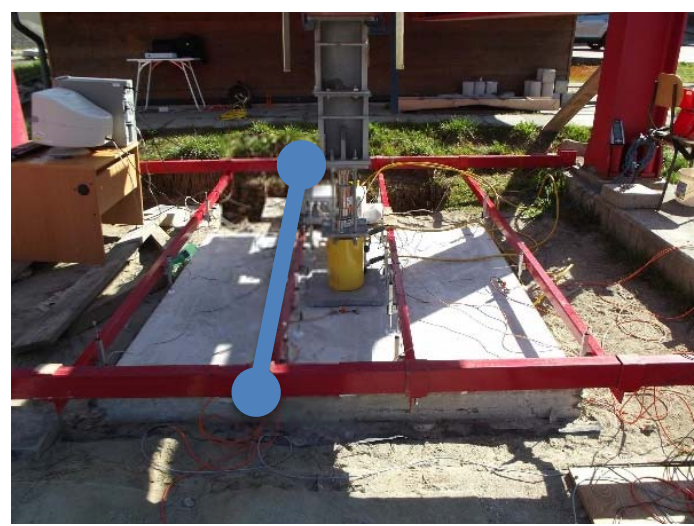

Fig. 4: Reinforcement concrete slab.

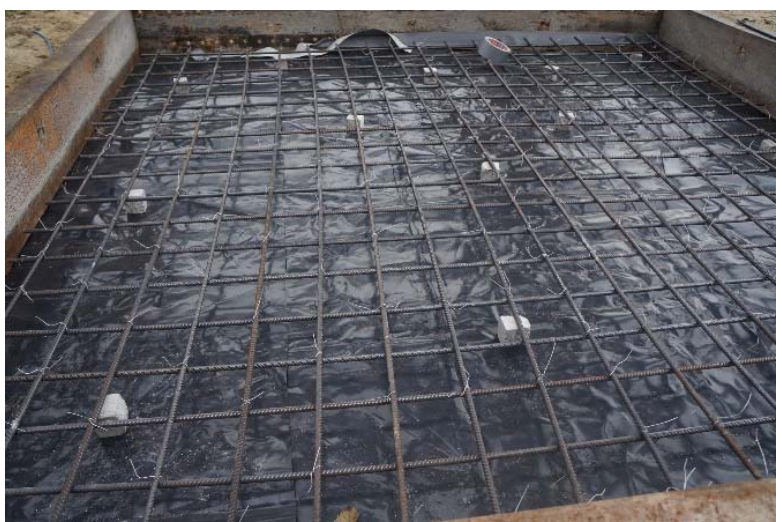

Fig. 5: Reinforcement - steel mesh.

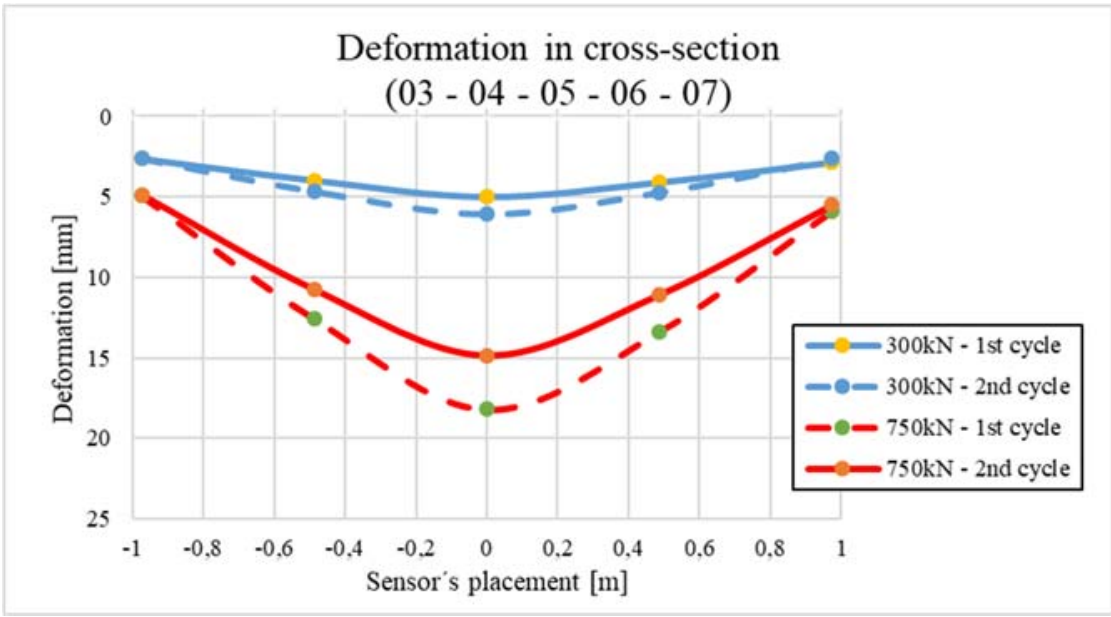

Fig. 6: Deformation of reinforcement concrete slab.

\section{Result}

In Tab. 1 shows the deformations for individual variants of the calculation with the numerical models, which have different modulus of elasticity subsoil and different depth of subsoil. The results table shows a greater influence on deformations when changing the modulus of elasticity of the subsoil than when changing the depth of the subsoil. The resulting deformations are significantly smaller when the modulus of elasticity of the subsoil increases. The resulting deformations for a load of $300 \mathrm{kN}$ are in the range of 3.92 to $10.91 \mathrm{~mm}$. For a load of $750 \mathrm{kN}$, the difference is even more pronounced from 12.32 to $40.02 \mathrm{~mm}$. Is evident influence of the development of cracks in the concrete and reduction of the bending stiffness of the concrete slab.

Tab. 1: Deformations of reinforcement concrete slab-parametric study.

\begin{tabular}{|c|c|c|c|c|c|c|}
\hline \multirow{2}{*}{$\begin{array}{c}\text { Modulus of } \\
\text { elasticity subsoil }\end{array}$} & \multicolumn{7}{|c|}{ Load [kN] } \\
\cline { 2 - 7 } & 300 & 750 & 300 & 750 & 300 & 750 \\
\cline { 2 - 7 } & \multicolumn{7}{|c|}{2} & \multicolumn{7}{|c|}{ Subsoil of depth [m] } \\
\hline 12.5 & 8.60 & 35.90 & 9.90 & 38.33 & 10.91 & 40.02 \\
\hline 22.5 & 5.28 & 17.07 & 6.00 & 18.92 & 6.57 & 20.48 \\
\hline 32.5 & 3.92 & 12.32 & 4.44 & 13.62 & 4.82 & 14.60 \\
\hline
\end{tabular}




\section{Conclusions}

Soil Structure Interaction solves a complex problem. In specific cases where it is necessary to take into account the real behavior of the structure and the subsoil, the solution leads to a non-linear analysis. In this case, suitable solutions include the use of the finite element method and 3D computational models. Sensitive input parameters include the mechanical parameters of the subsoil and also the choice of model geometry itself. However, under real foundation conditions, the SSI task is not geometrically limited. When selecting the subsoil model, it is necessary to the geological monitoring or exploration. The differences in the resulting deformations of the slab in individual variants of the calculation can are significant. Numerical calculations also showed that with the development of cracks in the concrete, the lowering of the rigidity of the slab and the increase in the load, the influence of the mechanical parameters of the subsoil increases. One of the specifics of the solved problem is that even after a significant failure of the concrete and plasticization of the reinforcement, but the reinforced concrete slab remained whole.

\section{Acknowledgement}

The work was supported by the conceptual development of science, research, and innovation assigned to VŠB-TUO by the Ministry of Education, Youth and Sports of the Czech Republic.

\section{References}

Augustin, T., Fillo, L., Halvonik, J. and Marcis, M. (2018) Punching resistance of flat slabs with openings experimental investigation. Solid State Phenomena, 272, pp. 41-46. doi:10.4028/www.scientific.net/SSP.272.41.

Buchta, V., Janulikova, M. and Fojtik, R. (2015) Experimental Tests of Reinforced Concrete Foundation Slab. Procedia Engineering, 114, pp. 530-537, doi:10.1016/j.proeng.2015.08.102.

Cajka, R. (2014) Comparison of the calculated and experimentally measured values of settlement and stress state of concrete slab on subsoil. Applied Mechanics and Materials, 501-504, pp. 867-876.

Cajka, R., Marcalikova, Z., Kozielova, M., Mateckova, P. and Sucharda, O. (2020) Experiments on Fiber Concrete Foundation Slabs in Interaction with the Subsoil. Sustainability 2020, 12, 9, 3939. doi:10.3390/su12093939.

Cervenka, V., Jendele, L. and Cervenka, J. (2016) ATENA Program documentation - Part 1: Theory. Cervenka Consulting. Pratur.

fib Model Code 2010, Final draft, fib, 2012, Bulletin no. 65 and 66, 1-2.

Hegger, J., Ricker, M., Ulke, B. and Ziegler, M. (2007) Investigations on the punching behaviour of reinforced concrete footings. Engineering Structures, 29, pp. 2233-2241. doi:10.1016/j.engstruct.2006.11.012.

Hoang, L. C. and Pop, A. (2016) Punching shear capacity of reinforced concrete slabs with headed shear studs. Magazine of Concrete Research, 68, 3, pp. 118-126.

Hrubesova, E., Mohyla, M., Lahuta, H., Bui, T.Q. and Nguyen, P.D. (2018) Experimental analysis of stresses in subsoil below a rectangular fiber concrete slab, Sustainability (Switzerland), 10, 7, art. no. 2216.

Kralik, J. (2016) Probabilistic safety assessment of the design of a tall buildings under the extreme load, AIP Conference Proceedings, 1738, art. no. 480088. doi:10.1063/1.4952324.

Kotrasova, K. and Kormanikova, E. (2017) Dynamic analysis of liquid storage tanks, AIP Conference Proceedings, 1863 , art. no. 260005. doi:10.1063/1.4992419.

Kozielova, M., Marcalikova, Z., Mateckova, P. and Sucharda, O. (2020) Numerical Analysis of Reinforced Concrete Slab with Subsoil, Civil and Environmental Engineering, 16, 1, pp. 107-118. doi: 10.2478/cee-2020-0011.

Pazdera, L., Cajka, R., Topolar, L., Mateckova, P., Bilek, V. and Sucharda, O. (2019) Measurement and Utilization of Acoustic Emission for the Analysis and Monitoring of Concrete Slabs on the Subsoil. Periodica Polytechnica Civil Engineering, 63, 2, pp. 608-620. doi:10.3311/PPci.12695.

Siburg, C. and J. Hegger, J. (2014) Experimental investigations on the punching behaviour of reinforced concrete footings with structural dimensions. Structural Concrete, 15, 3. doi:10.1002/suco.201300083.

Sucharda, O. (2020) Identification of Fracture Mechanic Properties of Concrete and Analysis of Shear Capacity of Reinforced Concrete Beams without Transverse Reinforcement. Materials 2020, 13, 12, 2788. doi: 10.3390/ma13122788.

Sucharda, O., Smirakova, M., Vaskova, J., Mateckova, P., Kubosek, J. and Cajka, R. (2018a) Punching Shear Failure of Concrete Ground Supported Slab. International Journal of Concrete Structures and Materials, 12, 1, art. no. 36.

Sucharda, O. and Konecny, P. (2018b) Recommendation for the modelling of 3D non-linear analysis of RC beam tests, Computers and Concrete, 21, 1, pp. 11-20. doi:10.12989/cac.2018.21.1.011.

Tomasovicova, D. and Jendzelovsky, N. (2017) Stiffness Analysis of the Subsoil under Industrial Floor. Procedia Engineering, 190, pp. 365-370, doi:10.1016/j.proeng.2017.05.350. 